\title{
ARTIGO
}

\section{Formação contínua de professores do ensino fundamental sob a ótica do desenvolvimento da information literacy, competência indispensável ao acesso à informação e geração do conhecimento}

\author{
Continuous education of elementary school teachers \\ from the perspective of information literacy \\ development, a competence indispensable to \\ information access and generation of knowledge
}

Regina Célia Baptista BELLUZZO

R E S U M O

Área de pesquisa de interesse bastante recente e ainda inexplorada no Brasil, a information literacy, ou seja, a competência no uso da informática, é considerada necessária aos professores do ensino fundamental, posto que relaciona-se à construção de significados a partir da informação, à proficiência investigativa e ao aprendizado independente, assim como ao aprendizado ao longo da vida. Este artigo tem por objetivo contribuir à melhor compreensão dessa matéria, centrando-se na discussão dos aspectos histórico-conceituais pesquisados, necessários à sua teorização, e nas suas possíveis aplicações nas práticas que envolvem a formação contínua dos professores do ensino fundamental, estes, sendo tanto usuários da informação, como geradores de conhecimento.

Palavras-chave: information literacy, formação de professores, ensino fundamental, gestão da informação e do conhecimento, proficiência em informática.

\footnotetext{
1 Professora Pesquisadora e Pró-Reitora Acadêmica da Universidade do Sagrado Coração. Rua Imã Arminda, 10-50, Jardim Panorama, 17011-160, Bauru, SP, Brasil. E-mail: rbelluzzo@usc.br

Recebido em 18/2/2004 e aceito para publicação em 15/4/2004.
} 


\section{A B S T R A C T}

Despite being a research area of quite recent interest and still unexplored in Brazil, information literacy is already regarded as an indispensable competence for primary school teachers, since it is related to the construction of meanings based on information, to investigative proficiency and to independent learning, as well as to life-long learning. The present article intends to contribute to a better understanding of the subject, discussing, not only the researched historical and conceptual aspects necessary for the theorization of this subject, but also its possible applications in the practices involving the continuous education of primary school teachers, who are both, users of information and generators of knowledge.

Key words: Information literacy, teacher education, elementary school, knowledge and information management.

\section{N T R O D U C Ã O}

Atualmente, a sociedade vem passando por rápidas e profundas alterações que têm se refletido nos mais variados setores, destacando-se: os avanços tecnológicos, a transformação dos paradigmas econômicos e produtivos e, em especial, as mudanças relacionadas aos paradigmas educacionais.

A visão educacional predominantemente tradicional, baseada no conceito-chave de que o professor transmite um conjunto fixo de informações aos alunos, está sendo substituída por um enfoque educacional voltado aos processos de construção, gestão e disseminação do conhecimento, com ênfase no "aprender a aprender" e na educação contínua. Desta forma, o acesso e uso da informação tornou-se indicador incontestável de atualidade e sintonia com as tendências atuais.

Por sua vez, do excesso de informações disponibilizadas surgem inúmeras necessidades de se preparar o ser humano para a melhor compreensão de: como definir suas necessidades informacionais e como buscar e acessar efetivamente a informação necessária; como avaliá-la face à sua pertinência e relevância; como organizá-la e transformá-la em conheci- mento; como aprender a aprender de forma contínua.

Essas necessidades levam a questionamentos que se referem à capacitação de pessoas em lidar com essa nova realidade de predomínio da informação, do conhecimento e do aprendizado ao longo da vida - a information literacy.

Fruto da associação de dois termos information e literacy - este neologismo vem surgindo cada vez mais na área de Educação e em Ciência da Informação, dependendo de sua mediação. Trata-se de tema extremamente novo e de grande importância para o cenário social atual, embora sua conceituação ainda deva ser objeto de maiores estudos em nosso contexto (BELLUZZO, 2001; DUDZIAK, 2002).

Desse modo, pode-se dizer que duas são as condições essenciais para tornar efetivo esse novo enfoque da educação: uma nova dimensão do currículo e um novo perfil para a formação de professores. Porém, como o ato de ensinar pressupõe o conhecimento por parte daquele que ensina, isso transforma o acesso e uso da informação - um processo diretamente ligado à pesquisa - uma necessidade intrínseca e que deve estar presente, em particular, nos programas de formação contínua em desenvolvimento, 
sendo exemplo disso o Programa de Educação Continuada (PEC) Formação Universitária, da Secretaria de Estado da Educação (SEE) (São Paulo).

Face a essas considerações iniciais, passa-se a apresentar o referencial teórico resultante de pesquisa/revisão bibliográfica realizado, tendo recaído a atenção desta sistematização nos seguintes questionamentos centrais:

- Com quais significados o conceito de information literacy tem sido incorporado no discurso, nas políticas e nas práticas dos cursos de formação contínua de professores do ensino fundamental ( $1^{\mathrm{a}}$ a $4^{\mathrm{a}}$ séries), considerados como aprendizes que ensinam?

- Quais os desafios que se colocam contemporaneamente a uma reflexão crítica sobre a information literacy como uma competência a ser desenvolvida em programas de formação contínua de professores do ensino fundamental ( $1^{\underline{a}}$ a $4^{\underline{a}}$ séries)?

Esses questionamentos acham-se fundamentados a partir do delineamento dos seguintes pressupostos:

Um perfil de competências/disposições representativas de qualidades e requisito profissionais e reconhecidos internacionalmente, como a information literacy, são importantes e desejáveis ao desempenho da função de professor de $1^{\underline{a}}$ a $4^{\underline{a}}$ séries do ensino fundamental em nosso contexto.

Tanto a formação básica/inicial como a continuada do professor precisam contribuir significativamente para o desenvolvimento da information literacy, competência considerada importante para o desempenho ideal dessa função.

Embora a information literacy seja um tema de largo interesse para a literatura internacional, existem carências de estudos e pesquisas de natureza exploratória em nosso contexto, especialmente no que se refere à sua definição e relação com a implementação de programas educacionais e informacionais.

Considerando-se o problema e os questionamentos decorrentes, bem como os pressupostos apresentados, o presente artigo, tem como propósito oferecer uma contribuição para avanços na perspectiva da construção de conceitos e princípios teórico-práticos, em torno de uma prática que venha contemplar a information literacy como competência indispensável à formação de professores do ensino fundamental.

\section{A information literacy sob a ótica da educação no novo milênio}

A educação, considerada como um processo mediador, é responsável pelo desenvolvimento da capacidade de explicitar os sentidos e significados que o ser humano percebe e internaliza em suas relações com a natureza onde se insere historicamente.

Para Delors (2001, p.16) cabe à educação "a missão de fazer com que todos, sem exceção, façam frutificar os seus talentos e potencialidades criativas, o que implica por parte de cada um, a capacidade de se responsabilizar pela realização do seu projeto pessoal".

Face aos progressos atuais e previsíveis da ciência e tecnologia, um conceito de educação ao longo da vida surge como uma das formas de acesso ao século XXI, em resposta ao desafio de um mundo em rápida transformação e às necessidades de se aprender a viver juntos em harmonia.

Essa nova versão da educação deve ser amparada por quatro pilares, de acordo com Delors (2001), a saber: aprender a conhecer, tendo em conta as rápidas alterações provocadas pelo progresso científico e as novas formas de atividade econômico-social, o que requer uma cultura geral, capaz de se constituir em passaporte para a educação permanente; aprender a 
fazer, o que se concretiza na aquisição não somente de uma qualificação profissional , mas uma competência mais ampla, preparando o indivíduo para enfrentar situações imprevisíveis e para o trabalho em equipe nas organizações e nas experiências sociais, permitindo o fortalecimento da relação escola-trabalho; aprender a viver juntos, mediante a transmissão de conhecimentos sobre a diversidade da espécie humana e levando as pessoas a tomar consciência das semelhanças e da interdependência entre todos os seres humanos, na busca de objetivos comuns; aprender a ser, para melhor desenvolver a personalidade de cada um, agindo cada vez mais com maior capacidade de autonomia, discernimento e responsabilidade pessoal, não negligenciando na educação nenhuma das potencialidades de cada indivíduo (memória, raciocínio, sentido estético, capacidades físicas e aptidão para a comunicação).

Todos esses pilares são aspectos intimamente ligados, de uma mesma realidade, apresentando-se essa educação ao longo da vida como o produto de uma dialética em várias dimensões:

Se, por um lado, implica a repetição ou imitação de gestos e de práticas, por outro é, também, um processo de apropriação singular e de criação pessoal. Junta o conhecimento não-formal ao conhecimento formal, o desenvolvimento de aptidões inatas à aquisição de novas competências. Implica em esforço, mas também traz a alegria da descoberta. Experiência singular de cada pessoa, ela é também a mais complexa das relações sociais, dado que se inscreve, ao mesmo tempo, no campo cultural, no laboral e no da cidadania (DELORS, 2001, p.107).

O atual período histórico tem como uma de suas principais marcas a profundidade e a rapidez da inserção das Tecnologias da Informação e da Comunicação (TIC's) que estão transformando muitos aspectos da vida cotidiana. Essa revolução tecnológica em curso é irreversível nos seus aspectos básicos. Entretanto, é preciso não the oferecer apenas um significado com base no enfoque tecnicista, pois, necessariamente, por estar inscrita numa opção econômico-política determinada - a mundialização do mercado - e na Sociedade da Informação (SI), além de ser um fenômeno tecnológico, apresenta-se consubstanciada em um determinado projeto político.

O Brasil, a exemplo da comunidade mundial, também demonstra a sua preocupação com a sociedade da informação em seu Livro Verde (SOCIEDADE..., 2000, p.5), onde há uma visão tripartide bem delineada a respeito dos choques sociais básicos: o da própria sociedade da informação, a universalização e interconectividade entre as pessoas, as questões de inovação e desenvolvimento social resultantes da civilização científica e tecnológica. A esse fenômeno complexo que se referem os diversos nomes tais como: Sociedade da Informação, Sociedade do Conhecimento (Knowledge Society), ou Sociedade Aprendente (Learning Society), ou seja qual for a sua denominação, é indispensável a prevenção das ênfases no enfoque analítico e nas propostas sócio-pedagógicas de todas as áreas de formação.

Leonardo Boff (2001) , ao prefaciar a obra de Assmann mencionou que,

A humanidade se desenvolve num único lugar, isto é, no mesmo planeta Terra, nossa casa comum. Os avanços das ciências da Terra e da Vida mudam nossa cosmologia, vale dizer nossa imagem do universo e da missão do ser humano dentro dele [...] Como socializar tais avanços? Como fazer para que os seres humanos se sintam inseridos e não vítimas da insensibilidade social e ética que comportam as lógicas de exclusão? [...] Como educar? Como aprender? A emergente sociedade do conhecimento radicaliza 
tais questões. Hoje sabemos, a partir das biociências e das teorias do cérebro/mente que aprender não pode se reduzir a uma apropriação dos saberes acumulados da humanidade [...] Processos cognitivos e processos vitais se encontram (BOFF, 2001, p.11).

Ênfase é oferecida por Assmann (2001, p.12)) no sentido de que, a educação, é fazer emergir as vivências do processo de conhecimento e, o produto dessa educação leva o nome de experiências de aprendizagem e, não apenas, a aquisição de conhecimentos supostamente já prontos e disponíveis para o ensino concebido como simples transmissão. Assim, dentre alguns aspectos relacionados a tais circunstâncias mencionadas por esse autor, podem ser destacados como pressupostos para reflexão e pesquisa:

Duas coisas precisam caminhar juntas em relação à educação: melhoria pedagógica e compromisso social.

A educação só consegue alcançar resultados esperados quando se preocupa com: a geração de experiências de aprendizagem, criatividade para construir conhecimentos e habilidades para saber "acessar" fontes de informação.

$\mathrm{O}$ analfabetismo hoje tem as seguintes dimensões a serem derrotadas: a lecto-leitura (saber ler e escrever); a sócio-cultural (saber em que tipo de sociedade se vive) e a tecnológica (saber interagir com máquinas complexas).

É preciso substituir a pedagogia das certezas e dos saberes pré-fixados por uma pedagogia da pergunta, do melhoramento dessa pergunta e do acesso às informações. O conhecimento nunca é pura operação mental e toda ativação da inteligência está entretida de emoções.

Informação e Conhecimento se transformaram em fator produtivo mais relevante no contexto da mundialização das economias. É inegável que o acesso à informação e ao conhecimento, ou seja, a transformação de todos em seres "aprendentes", passa a ser condição indispensável à participação dos resultados dos produtos científicos e tecnológicos.

Em meio à essa necessidade de "aprender a aprender" que caracteriza a sociedade hoje, destaca-se a questão do desenvolvimento de competências para fazer frente aos novos desafios decorrentes de ambiência de grandes inovações que, de acordo com Perrenoud (1999, p.9) devem ser entendidas como a "capacidade de agir eficazmente em determinado tipo de situação, apoiada em conhecimentos, mas sem limitar-se a eles".

As dificuldades desse processo residem na gestão das vivências e práticas que requerem um planejamento estratégico, estruturado nas análises do macro e microambientes dos contextos envolvidos. No que se refere à information literacy, pode-se dizer que é um assunto ainda emergente e que se ressente da existência de base teórica nessa direção, com apoio de pesquisas e estudos de teor científico.

A American College and Research Libraries, também desenvolveu um programa de ação intitulado "ACRL Best Practices Initiave Characteristics of Program of Information Literacy" (disponível em www.ala.org/acrl/nili/ bestprac.html) que ilustra e recomenda detalhadamente quais são as melhores práticas para o desenvolvimento da competência no acesso e uso da informação nas bibliotecas, preconizando o trabalho conjunto entre os profissionais da informação e os professores.

Severino (2000), por sua vez, coloca também que

A questão da competência é entendida como domínio de conteúdos, dos métodos, das técnicas, das várias ciências, enfim, das habilidades específicas de cada área de formação e de cada forma de saber e de cultura [...] Continuam sendo metas a serem 
encaradas com seriedade, no âmbito da educação brasileira, a qualificação do ensino, o rigor da aprendizagem, a iniciação à pesquisa e a superação de todas as falhas decorrentes da falta de rigor científico no processo de ensino [...] Por isso, fica claro que o objetivo é aprender, é obter conhecimentos, é dominar produtos da ciência e, até mesmo, dominando seus métodos, criar ciência (SEVERINO, 2000, p.16).

Por outro lado, analisando-se o conceito de competência no contexto social, sob a ótica da economia globalizada, pode-se atribuí-lo a diferentes elementos. De um lado, as organizações com sua gênese, processos de desenvolvimento e seu patrimônio de conhecimento, o que lhes confere a vantagem competitiva. No outro extremo, temos as pessoas, com seu conjunto de competências individuais, definidas por Fleury (2000) como o saber agir de maneira responsável, implicando em mobilizar, integrar, transferir conhecimentos, recursos, habilidades que agreguem valor social ao indivíduo. Nas práticas organizacionais, de modo geral, a despeito da íntima relação entre as competências coletivas e as individuais, as decisões sobre as pessoas são tomadas em razão do que elas "entregam para a organização", enquanto que o sistema formal concebido, apenas busca privilegiar o que as pessoas "conseguem fazer, executar".

Senge (1990) fez comentários sobre a vinda do ser humano ao mundo, considerando que todos temos motivação natural para aprender, para explorar e experimentar novas descobertas. Para esse autor o processo de aprendizagem corresponde a um ciclo contínuo, composto de três conjuntos de elementos: aptidões e habilidades; conhecimentos e sensibilidades; atitudes e crenças. Assim, a partir do desenvolvimento de novas habilidades e aptidões, altera-se a compreensão do ser humano sobre a realidade. Novos conhecimentos e sensibilidades, quando incorporados, modificam os modelos mentais das pessoas, compostos por idéias profundamente internalizadas, generalizações ou até mesmo imagens que influenciam nossa visão de mundo e nossas atitudes.

Tendo como fundamento as linhas de pensamento de Senge (1990), Fleury (2001) mencionou que novas crenças e atitudes baseadas na interpretação da realidade poderão surgir e enriquecer esse mecanismo, o que estimula o desenvolvimento contínuo de habilidades e aptidões que, por sua vez, realimentam todo o sistema de aprendizado, transformando-o em um ciclo reforçador. As etapas de ação e reflexão alimentam-se mutuamente. A geração e aplicação do conhecimento ocorrerão, portanto, a partir da seqüência contínua dessas etapas.

Mas, como fazer para ensinar a aprender a gerenciar a grande massa de informação que, de acordo com estudo realizado recentemente pela Universidade de Berkeley (EUA), é um volume de conteúdos, produzidos em todo mundo a cada ano e em diferentes suportes, que está exigindo para ser arquivado, cerca de 1,5 milhão de gigabytes de memória? Essa massa de informação, se fosse dividida para cada pessoa sobre a Terra - homens, mulheres e crianças - equivaleria a 250 megabytes per capita por ano. Certamente, jamais, em toda a história o homem teve as facilidades atuais para criar tanta informação. Entretanto, o que nos preocupa é que essa condição suplanta e muito a habilidade em pesquisar, organizar e disseminar a informação registrada. A gestão da informação - nos diferentes níveis: pessoais, organizacionais e sociais - é o grande desafio dos tempos atuais, constituindo-se no próximo estágio de "alfabetização do homem".

Em decorrência dessa massa de informação, por sua vez, existe o conhecimento disponível para o Ser Humano que , igualmente, aumenta a cada dia, levando-nos a uma sensação de infinito nesse sentido. Porém, a nossa capacidade de reter, perceber ou sentir todos esses significados e significações, inseridos na Informação e no Conhecimento, é finita. Assim, é necessário contar com uma grande capacidade 
de seleção e discernimento para dar conta desse cenário, dependendo da fase de vida que cada um esteja atravessando e respectivas prioridades, bem como dos diferentes papéis que as pessoas representam ao longo de suas existências.

Recomenda-se, portanto, destacar, dentre as competências que o processo de ensinoaprendizagem deve estar centrado, a information literacy. Recomendada no Livro Verde Sociedade... (2000), essa competência constitui-se na fluência científica e tecnológica e no saber utilizar a informação, criando novo conhecimento.

Para Bazzo (2001) a ciência e a tecnologia se baseiam em valores do cotidiano de cada época, colocando em questão a maioria das convicções e conhecimento de mundo das pessoas. São a aplicação sistemática de alguns valores humanos, tais como a diligência, a dúvida, a curiosidade, a abertura para novas idéias, a imaginação, além de outros como a disciplina e a perseverança, que precisam ser despertados em todos os seres humanos. Portanto, não são apenas os chamados "pesquisadores" inseridos nas lides da pesquisa e em ambientes acadêmicos que devem respeitálos e entendê-los. É preciso que todas as pessoas sejam conscientizadas do amplo universo que a ciência e a tecnologia incorporam e sua relação direta com o grau de importância para o avanço do conhecimento, bem-estar e riscos e oportunidades sociais.

Todo ser humano, enquanto pessoa e cidadão, merece aprender a ler e entender - muito mais do que simples conceitos estanques - a ciência e a tecnologia, suas implicações e conseqüências, para poder ser elemento participante nas decisões de ordem político e social que influenciarão o seu futuro e o de outras gerações. Para tanto, assessorado pela mediação da educação formalizada, deve investir na construção de um conhecimento crítico e consistente, voltado ao seu próprio aprimoramento individual, mas também ao bem-estar da coletividade. Nesse aspecto, é que se pode ressaltar o desenvolvimento da competência denominada information literacy, tema em debate na Sociedade da Informação e do Conhecimento.

Uma definição para a information literacy pode ser encontrada na Association for College and Research Libraries (2000), que se reproduz a seguir: Information Literacy é definida como a habilidade para reconhecer, quando existe a necessidade de se buscar a informação, estar em condições de identificá-la, localizá-la e utilizá-la efetivamente para um objetivo específico e pré-determinado - o desenvolvimento da sociedade com responsabilidade, ética e legalidade. Também denominada de alfabetização do Século XXI. (tradução nossa).

Com apoio nas afirmações de Demo (1998, p.207) pode-se dizer que a information literacy implica principalmente no desenvolvimento de:

- Habilidade de propedêutica (raciocínio completo e questionador, capaz de pesquisar e elaborar individualmente $=$ qualidade formal).

- Habilidade de intervir na realidade (criticar e usar a criatividade, introduzindo permanentemente a inovação = qualidade política).

- Habilidade emocional (envolvimento subjetivo, capaz de se traduzir em auto-estima, realização individual e coletiva).

- Habilidade em saber fazer (demonstrar corretamente o saber pensar).

Tais habilidades fornecem a condição de se exercer a autonomia intelectual, condição essencial para as exigências das capacidades de: iniciativa, decisão, domínio cultural (geral e técnico), domínio lógico (saber pensar e resolver) e psicológico (perceber os significados e significações), permitindo aprender a aprender, assimilando, criticando e aprimorando a ciência e a tecnologia. Para tanto, é necessária a fluência científica e tecnológica que deve estar presente em todos os estágios de uma pesquisa científica, 
caracterizada como sendo "uma atividade intelectual que visa responder às necessidades humanas" (SANTOS, 1999, p.15).

Entretanto, ressente-se a sociedade contemporânea de uma política social mais integrada às conquistas do homem no campo científico e tecnológico como produto de pesquisas, havendo a necessidade de se retomar a sintonia entre a ciência e o seu aspecto humano, tratando-a como um processo global dentro de um contexto e não apenas um mero produto, de utilização determinada, independente de suas repercussões.

Em decorrência, ao se falar em uma nova orientação de ordem educacional, o problema assume um caráter mais preocupante, pois, além das conseqüências de ordem prática que este posicionamento pode causar, existem também as questões de ordem cognitiva relativas à compreensão, pois, qualquer coisa, em qualquer campo do conhecimento, só será valorizada, qualificada e utilizada criticamente, quando, de fato, for compreendida e internalizada, provocando a mudança de comportamento.

As avaliações da ciência e da tecnologia e de seus impactos na inovação e desenvolvimento da sociedade precisam seguramente tomar novos rumos, mais claros e intensos nas atividades educacionais. Não é mais possível, e menos indicado, que haja uma permanência, um estado contemplativo à espera do inexorável desenvolvimento científico e tecnológico. É mister que haja a potencialização dos conteúdos nessa área, nos diferentes níveis educacionais, a fim de se conseguir incrementar o grau de "cultura científico-tecnológica” desejável, permitindo que a maioria dos cidadãos , em especial do nosso país, possa se sentir atraída pela produção e reflexão permanente de seus resultados, adotando verdadeiramente uma postura científica.

Essa "maneira científica" de ver o mundo supõe um esforço mental que se conhece por racional, atribuindo-se essa atitude como um fruto de conquista histórica do homem ao longo dos tempos. Autores como Santos (1999, p.61), preocupados com essa questão mencionam que o cérebro humano é capaz de diferentes estágios ou estados cognitivos diversos, com graus de complexidade diversificados. São eles: conhecimento, compreensão, aplicação, análise, síntese e avaliação.

Transferindo-se esses conceitos para o Processo de Pesquisa, acredita-se que a fluência científica e tecnológica deve estar presente em todas as suas etapas e instâncias, conforme se representa na Figura 1.

Apenas para ilustrar melhor o grau de importância e de complexidade da information literacy, em todas as etapas e instâncias indicadas graficamente no modelo circular descrito, em especial, salienta-se a questão do pensar criticamente e criar. Para esse fator do processo de pesquisa, a literatura especializada internacional aponta 35 indicadores, já consagrados, envolvendo estratégias para o desenvolvimento de habilidades e aptidões de natureza afetiva e cognitiva que devem ser incorporadas aos objetivos de ensino-aprendizagem, (http:// www.criticalthinking.org/K12/html). Além disso, são apontadas também três áreas básicas para que se estabeleçam diferenças à compreensão do "pensar criticamente e o não pensar criticamente" (Quadro 1).

Para que as pessoas aprendam e desenvolvam as competências que se acham representadas no processo de pesquisa e seus estágios (Figura 1), atendendo às necessidades individuais e coletivas de construção do conhecimento com discernimento e face à contextualização da realidade social em que vivemos, é preciso que seja desenvolvida uma nova dimensão do aprender, onde o desenvolvimento do raciocínio, da capacidade de criação e inovação possam ser priorizados. Ensinar a aprender, muito mais do que ensinar a fazer. 
Quadro 1. Diferenças entre o pensamento crítico e o não crítico.

\begin{tabular}{lll}
\hline Pontos de Vista/Estratégias & Pensamento Crítico & Pensamento Não Crítico \\
\hline \multirow{3}{*}{ Conhecimento } & Área cinza/esforço para o & Branco e preto/Campo \\
& Aprofundamento & Superficial \\
& Interdisciplinar & Unidisciplinar \\
& Aberto & Fechado \\
& Associação de Idéias & Pensamento Independente \\
\hline & Racional e Consistente & Irracional e Inconsistente \\
& Esforço para Aprender Como & Esforço para Aprender O Que \\
& Pensar & Pensar \\
& Holístico/sistêmico & Unidisciplinar/Linear \\
& Original/Discernimento & Pensamento Secundário \\
& Múltiplos Quadros de & Quadro Único de \\
& Referência & Referência \\
\hline & Ultrapassar bloqueios & Esforço para Bloquear \\
& Explorar/Investigar & Dogmático \\
& Questionar & Duvidoso \\
Imparcialidade & Ego-etnocêntrico-emocional \\
& Ativo & Passivo \\
& Colaboração/Interação & Autoritário \\
& Linguagem Precisa & Linguagem Imprecisa \\
\hline
\end{tabular}

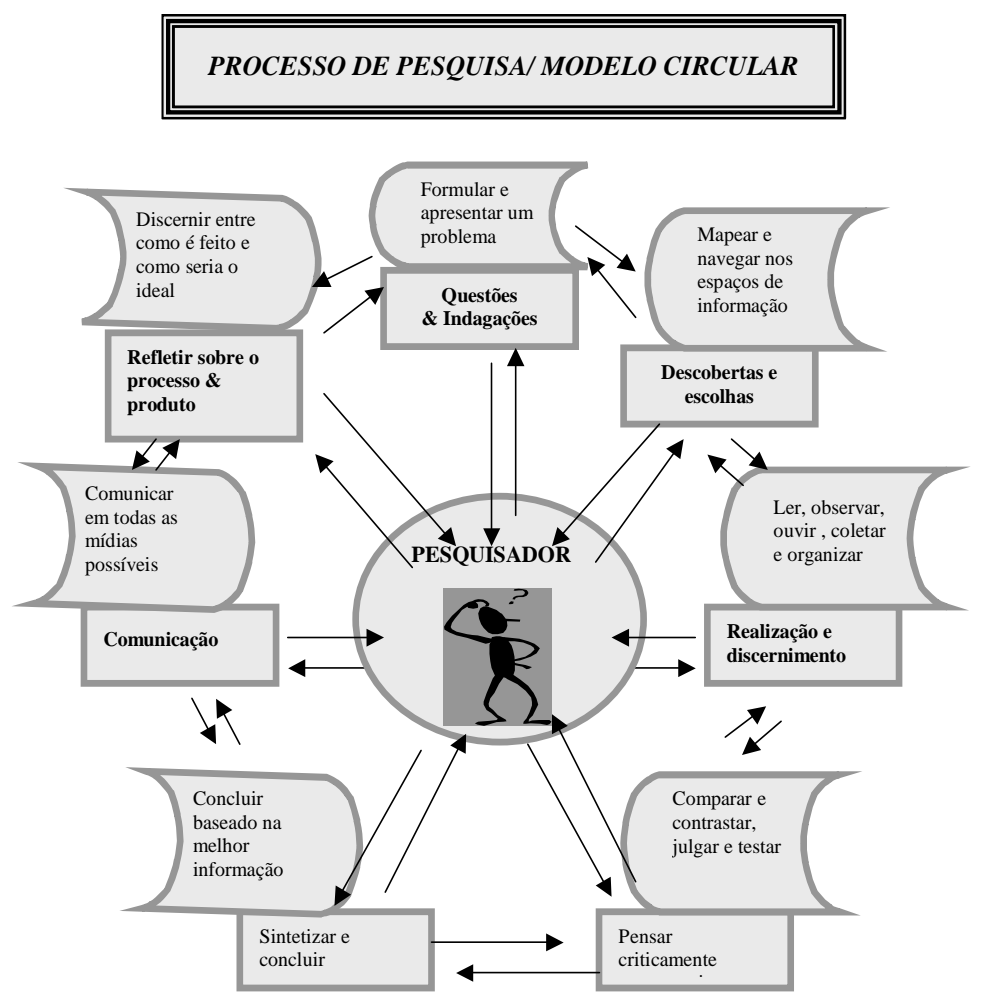

Figura 1. Processo de Pesquisa em Perspectiva Circular. Adaptado de Loertscher, D. California Technology Assistance Project. 
Historicamente, a questão da formação de professores é um assunto on demand, tendo ganhado maior relevância no processo de formulação do Plano Decenal de Educação para Todos (1993-2003), onde se destacou a importância da profissionalização das ações do Ministério de Educação e outras organizações administrativas ligadas à educação (PROMELAC $V$ citado por AGUIAR, 2001). Considerou-se que essa profissionalização corresponderia ao desenvolvimento sistemático da educação fundamentado na ação e no conhecimento especializados, de maneira que a tomada de decisões sobre o que se aprende, o que se ensina e qual a arquitetura organizacional é a mais adequada. Além disso, essas práticas devem estar de acordo com:

- Progresso dos conhecimentos científicos e técnicos, de modo que as ações realizadas estejam fundamentadas na acumulação e aplicação de conhecimentos, sejam eles específicos ou polivalentes.

- O quadro de responsabilidades preestabelecidas, de modo que as ações sejam executadas e ocorram com pleno conhecimento do que delas se espera e que, conseqüentemente, possam ser submetidas normalmente à avaliação de resultados por parte dos superiores, dos pares, dos próprios envolvidos ou da comunidade.

- Os critérios éticos que regem a atividade, de modo a aumentar a responsabilidade individual, acrescentar a confiança da comunidade e a credibilidade da profissão. Os diversos contextos e características culturais, que são os que dão sentido e conteúdo específico às ações (CASASSUS, 1994 citado por AGUIAR, 2001).

Estava claro para o governo brasileiro, entretanto , que a qualificação da oferta pública da educação básica exigiria uma ação programada e articulada da União, estados e municípios quanto à valorização do magistério e a melhoria do desempenho dos quadros dirigentes. Assim, a Secretaria de Ensino Fundamental (SEF), em articulação com outros setores do Ministério de Educação (MEC) definiu diretrizes para a capacitação de professores, dirigentes e especialistas em educação básica (MEC/SEF citado por AGUIAR, 2001, p.195).

Kuenzer (1999), ao desenvolver pesquisas buscando identificar as mediações entre as mudanças que ocorrem no mundo do trabalho e as novas demandas para a escola em todos os níveis, chamou a atenção para a necessidade de se partir para uma formação mais rigorosa, com sólidos fundamentos gerais, comum a todos os profissionais do ensino médio e profissional, sob tal ótica. Mencionou que essa formação deveria contemplar os seguintes eixos:

- Contextual: articulando os conhecimentos sobre educação, economia, política e sociedade, e suas relações, tomadas em seu desenvolvimento histórico.

- Institucional: contemplando as formas de organização dos espaços e processos educativos escolares e não-escolares.

- Teórico-prático: integrando conhecimentos relativos a teorias e práticas pedagógicas, gerais e específicas, incluindo cognição, aprendizagem e desenvolvimento humano.

- Ético: compreendendo as finalidades e responsabilidades sociais e individuais no campo da educação, em sua relação com a construção de relações sociais e produtivas segundo os princípios de solidariedade, da democracia e da justiça social.

- Investigativo: comprometido com o desenvolvimento das competências em pesquisa, tendo em vista o avanço conceitual na área da educação (KUENZER, 1999).

Pode-se afirmar, a exemplo de Villardi (1999), que a formação do professor e as questões que se acham envolvidas em torno dessa temática, não podem estar dissociadas da discussão sobre o enfoque da "formação do leitor", por considerar a sua importância num 
contexto cultural em que a transmissão e produção do saber se alicerçam na linguagem e no espírito investigativo.

Tradicionalmente, a formação inicial de professores, no contexto brasileiro, tem compreendido, via de regra, que o futuro profissional aprenda a transmitir (ordem do conteúdo) adequadamente ( ordem didática) as informações que seu futuro aluno precisa ter. Assim, parece ser um contra-senso exigir do licenciado um espírito investigador e criativo, que possa viabilizar a construção do pensamento científico em seus alunos, quando ele mesmo não vivenciou esse tipo de experiência, considerando-se os paralelos e contrastes que existem no contexto brasileiro no que diz respeito à existência de bibliotecas escolares e questões de incentivo à leitura.

$\mathrm{O}$ ato de ensinar pressupõe o conhecimento por parte daquele que ensina, o que transforma a pesquisa numa necessidade intrínseca para o ensino-aprendizagem. Nesse sentido, as novas tecnologias parecem estar contribuindo para redimensionar o papel do professor, instando-o a atuar de modo a conduzir o aluno a um tipo de conhecimento que cada vez mais se afasta da mera informação, a um tipo de conhecimento capaz de levá-lo a outros conhecimentos. Para tanto, é preciso que esse professor seja um pesquisador, em sentido amplo, que tenha desenvolvido as habilidades inerentes a uma atitude inquieta, investigativa, reflexiva e crítica (VILLARDI, 1999).

A tradição, que proclama essa necessidade de geração do conhecimento na mente de professores, tem sua origem nos Estados Unidos, quando ao final do século XIX, Dewey criou uma "escola experimental" onde os professores colocavam à prova os princípios de uma educação para a democracia. Na década de 70, Stenhouse (1998, p.133) considerou que "se trata de que a investigação e o desenvolvimento do currículo devem corresponder ao professor e que existem perspectivas para levar isto à prática".
No último informe da UNESCO (DELORS, 1996, p.172) reconhece que "dada a importância da investigação para a melhoria qualitativa do ensino e da pedagogia, a formação do pessoal docente tem que compreender um elemento reforçado de formação em investigação".

Messina (1999), em trabalho que apresenta o estado da arte da pesquisa acerca da formação docente na América Latina durante os anos noventa, considerando uma amostra de 100 casos de estudo, afirmou que "a reivindicação da pesquisa como um elemento indispensável da formação inicial e em serviço, é proposto, pelo menos, em um terço das investigações identificadas", o que indica a relevância que tem a pesquisa na formação de professores.

Outros autores, como Rodriguez; Bernal (2001), ao estudarem os professores em contextos de investigação e inovação, fazem um retrospecto na base de dados ERIC, quando encontraram cerca de 117 mil registros nos descritores consultados (teacher, investigator, researcher e innovator). Desse total, apenas 4.213 realmente puderam ser selecionados por estarem especificamente relacionados ao tema "professor como pesquisador". Porém, ainda, apenas um grupo muito restrito desses textos realmente estudava o professor enquanto pesquisador e inovador, sendo destacados, na última década, os trabalhos de:

- Brindeley (1991) - análise das percepções de professores principiantes em pesquisa e dos problemas que eles encontram em seu exercício.

- Belanger (1992) - análise dos diferentes papéis que pode exercer um professor em uma pesquisa, tecendo considerações sobre alguns benefícios de ordem política, prática e profissional que são obtidos pelas pessoas que participam de projetos de investigação científica.

- Reimer; Bruce (1993) - análise das dimensões éticas da pesquisa, a função específica dos professores e pesquisadores e algumas das limitações institucionais e de 
tempo que são encontradas para o desenvolvimento de pesquisa na escola. Apontam uma lista de condições para o êxito da pesquisa nos ambientes educacionais.

- Fueyo; Koorland (1997) - apresentação de problemas para se implementar a pesquisa na formação de professores e nas escolas e propõem um plano de ação para promovê-la.

- Coombs (1999) - destaque para a importância de fazer dos professores verdadeiros pesquisadores em sala de aula e geradores de teorias de aprendizagem.

Para Laranjeira et al. (1999), de modo geral, a formação dos professores deve ser entendida como um processo contínuo e permanente de desenvolvimento, o que pede: do professor, disponibilidade para a aprendizagem; da formação, que o ensine a aprender; e do sistema educacional, as condições para continuar aprendendo. Essa formação compreende diferentes etapas: inicial (integrada a uma organização curricular e institucional, capaz de estabelecer uma ligação entre a escola de formação e o sistema de ensino fundamental, convertendo-se as disciplinas cursadas em referência para uma atuação profissional); capacitação em exercício (visa qualificar professores que estão atuando profissionalmente, dependendo da escolaridade que possuam, possibilitando que os conhecimentos profissionais sejam trabalhados em níveis de profundidade que de fato possam trazer um ganho diferenciado na sua possibilidade de compreenderem e atuarem na profissão; continuada (intimamente ligada à existência de projetos educacionais nas escolas de educação básica e pode acontecer tanto no trabalho sistemático na escola ou fora dela, mas sempre com repercussão em suas atividades).

Inserido nesse processo de formação continuada e como parte de política educacional do MEC, acha-se o Programa PEC - Formação Universitária, da Secretaria de Estado da Educação do Estado de São Paulo (SÃO
PAULO..., 2001). Essa proposta acha-se pautada no intuito de dar continuidade às ações de valorização profissional do magistério paulista e pelo fato da Secretaria da Educação entender que a formação de professores do ciclo inicial do ensino fundamental deva ser realizada em nível superior, o que é preconizado pela nova Lei de Diretrizes e Bases da Educação Nacional (LDB) (Lei 93394/96), em seu artigo 62. Assim, para implementar esse princípio, a LDB institui, nas duas disposições transitórias, a década da educação, finda a qual somente serão admitidos professores habilitados em nível superior ou formados por treinamento em serviço (Artigo 87, parágrafo $4^{\circ}$ ) e indica como um dos eixos de atuação realizar programas de capacitação para todos os professores em exercício, utilizando também, para isso, os recursos de educação à distância (Artigo 87, parágrafo $3^{\circ}$, inciso III).

Como resultado disso, o Governo do Estado de São Paulo, a exemplo de outras experiências nos demais estados brasileiros, criou o Programa Especial de Formação de Professores de $1^{\underline{a}}$ a $4^{\underline{a}}$ séries do Ensino Fundamental, com ênfase no estudo dos conhecimentos relativos às áreas curriculares, visando o aprimoramento e qualificação da sua atuação na rede oficial de ensino.

O Estado de São Paulo tem 42,2\% de docentes PEB I efetivos, dos quais 26.700 têm formação em nível superior e 12.400 em nível médio (SÃO PAULO, 2001). Desse modo, a Secretaria, através do desenvolvimento do PEC, pretende dar continuidade à formação desse contingente de docentes efetivos que apresentam formação de nível médio, considerando e aproveitando a larga experiência profissional que esses profissionais possuem.

O PEC-Formação Universitária tem como princípios educacionais, político-institucionais e pedagógicos o que segue:

- A formação dos professores deve estar articulada com a adequada provisão de recursos pedagógicos, de infra-estrutura tecnológica e a busca da integração com a comunidade. 
- O exercício da docência escolar deve ser a referência da organização institucional e pedagógica do programa de formação de professores.

- Os professores são agentes fundamentais na implementação da política educacional da SEE.

- As parcerias com outros setores da sociedade são importantes na consolidação das políticas da SEE. No que se refere à formação de seus recursos humanos, a Universidade e/ou Instituição de Ensino Superior constitui-se em um interlocutor privilegiado para discussão e concretização de suas propostas.

- Os Parâmetros Curriculares Nacionais devem ser tomados como referência na formação do professor multidisciplinar.

- A construção de competências deve ser o eixo organizador do currículo.

- A coerência entre a formação do professor e a prática de atuação que dele se espera deve pautar todas as atividades que serão desenvolvidas durante o programa.

- O domínio dos objetos sociais do conhecimento e a sua transposição midiática devem ser priorizadas.

- A dimensão da pesquisa na formação do professor deve garantir o desenvolvimento de uma postura de investigador que leve à reflexão sobre sua ação cotidiana.

Segundo Zeichneir (1993), numa das concepções de prática reflexiva cinco dimensões podem ser destacadas para a formação de professores. Inicialmente, a forma como se considera o processo de reflexão: a reflexão na ação, na deliberação curricular; no conteúdo da reflexão: os valores próprios dos professores, o contexto societal, a teoria educacional; nas condições prévias à reflexão: as atitudes para reflexão, o contexto de orientação no qual ocorre a reflexão; no produto da reflexão: eficiência no ensino e a forma como os conceitos têm sido justificados, defendidos e relacionados ao contexto de formação profissional. Gómez (1992, p.106) mencionou que o "pensamento prático do professor é de importância vital para compreender os processos de ensino-aprendizagem, para desencadear uma mudança radical dos programas de formação de professores e para promover a qualidade do ensino na escola numa perspectiva inovadora".

\section{CONSIDERA ÇÕ ES FINA IS}

Apoiados nas afirmações de Miranda (1999) podemos dizer que a prática da educação continuada sempre esteve presente nas políticas e planos educacionais. Porém, até recentemente, predominava o conceito de reciclagem ou de treinamento, com o objetivo de atualização de práticas e de teorias mais recentes de diferentes conteúdos. Hoje, busca-se alcançar práticas mais avançadas que partem de uma concepção baseada na metodologia circular ação - reflexão - ação, onde o ponto de partida é a própria vivência do professor para, em seguida serem introduzidas estratégias de reflexão orientada que, além de informar o fazer do professor, permitem analisar criticamente essa prática. Assim, o professor volta à sua atuação profissional com alternativas que recria e pode transformar em ações aperfeiçoadas.

Norteados por essa nova concepção, pode-se concluir que os programas de capacitação de professores têm se orientado para:

- A necessidade de resgatar, de valorizar o saber fazer do professor e o que ele acumulou na sua prática profissional.

- A consideração de que a educação continuada deve ser tratada como direito do professor, enquanto categoria de trabalho, e como instrumento de valorização do trabalho docente e de sua realização profissional.

- A consideração de que a escola é o local privilegiado para ações de capacitação. 
- A adoção de princípios democráticos na elaboração de programas de capacitação, principalmente deixando que os próprios professores explicitem suas necessidades, carências e suas demandas de cursos e ações.

- A construção de espaços significativos de educação continuada em cada escola, onde a influência do contexto e das relações interpessoais que estão presentes nas possibilidades de intercâmbios e trocas de experiências entre colegas, seja em reuniões internas ou em contatos pessoais, momentos de aprendizagem, de reflexão e de críticas (MIRANDA, 1999).

$\mathrm{Na}$ direção dessa avaliação, Miranda (1999) apresenta algumas reflexões sobre a avaliação externa do PEC, da qual participou como membro de equipe da Fundação João Pinheiro. Percebe-se uma ênfase à necessidade dessa avaliação e às principais dificuldades para o estabelecimento de categorias representativas na dinâmica de construção progressiva desse processo. Ao final, foram apontadas as quatro experiências consideradas mais coletivas: o Programa da Universidade Estadual Paulista UNESP/Bauru, o do Instituto Paulo Freire, a Semana Pedagógica da Delegacia de Ensino de Tupã (SP) e um evento da Universidade Federal de São Carlos (UFSCAR).

Ressalte-se, desse modo, que a concepção de educação continuada que fundamentou o PEC pode ser considerada bastante inovadora, pois, parte do saber acumulado dos professores e não supondo que todos sejam homogêneos, não propondo um programa único de capacitação para todo o Estado. Antes, deixa a critério de cada Diretoria de Ensino a escolha dos temas que devem ser objeto do curso, recomendando que elas façam parcerias com as universidades, que elas acompanhem e avaliem constantemente as suas ações.

Em relação a esse último ponto - questão da avaliação do PEC - é o que consideramos ser de relevância e interesse, por se entender que esta é uma área que, em nossa pesquisa/ revisão bibliográfica apontou que há carência de estudos e práticas que possam contribuir para sanar dificuldades que são mencionadas por Miranda (1999), ao apresentar reflexões sobre avaliação externa do programa e, Azevedo (1999), ao estudar o programa desenvolvido nas diferentes unidades da UNESP. Isso se acentua, quando se relaciona à avaliação do desenvolvimento da information literacy - competência que se encontra tacitamente presente e se acha recomendada em toda a sistemática curricular do PEC, ao se incluir a obrigatoriedade da existência da dimensão da pesquisa na formação do professor que "deve garantir o desenvolvimento de uma postura de investigador que leve à reflexão sobre sua ação cotidiana" (SÃO PAULO, 2001).

A presença de uma cultura da informação nesses programas de formação continuada do professor, certamente, é o resultado de uma nova mentalidade e de uma nova tecnologia ou forma de produção. Desse modo, essa nova cultura é uma das experiências da sociedade contemporânea, constituindo-se em processo dinâmico, que possibilita: melhoria na capacidade intelectual; desenho e desenvolvimento dos meios e das formas de comunicação para a gestão do conhecimento; impulso na compreensão e no entendimento, não somente na socialização da informação, cuja finalidade é incrementar o repertório de conhecimentos e experiências das pessoas e das atividades humanas. Entretanto, é preciso criar uma ambiência ideal à concretização dessa nova cultura, representada como segue:

- Ênfase no aprender a aprender como formular questões, estar aberto a novos conceitos, como acessar a informação; saber como o "conhecer" pode se alterar.

- O aprendizado é um processo; os aprendizes tomam decisões a respeito do aprendizado e são encorajados a serem autônomos e independentes. 
- As abordagens de aprendizado são flexíveis e se coadunam com as características e comportamentos dos grupos de aprendizado.

- O aprendizado teórico é complementado pela experimentação, dentro e fora da sala de aula onde a leitura é condição fundamental.

- O professor é um facilitador de relacionamento baseado na troca de informações. A informação cria significado e compreensão, habilita os aprendizes a encontrar o sentido das situações: os significados variam de pessoa para pessoa.

- O professor, enquanto usuário da informação, está ativamente envolvido com a produção e transferência da informação e o profissional da informação é o mediador deste processo, em busca da satisfação das suas necessidades informacionais.

- As bibliotecas e outras unidades de informação devem ser vistas como sistemas aprendentes, centros de aprendizado e possuir ambientes multiculturais.

\section{RE FERÊ N C IAS}

AGUIAR, M.A.S. Gestão da educação e a formação do profissional da educação no Brasil. In: FERREIRA, N.S.; AGUIAR, M.A.S. (Org.). Gestão da educação: impasses, perspectivas e compromissos. 2.ed. São Paulo: Cortez, 2001. p.193-210.

ASSMAN, H. Reencantar a educação: rumo à sociedade aprendente. 5.ed. Petrópolis: Vozes, 2001.

ASSOCIATION FOR COLLEGE AND RESEARCH LIBRARIES. Information literacy competency standards for higher education: standards, performance, indicators, and outcomes. ACRL Board, January. 2000. Available from: <http:// literacyindicatorsala.htm>. Acess: 28 Jul. 2001.

ASSOCIATION FOR COLLEGE AND RESEAR LIBRARIES.ACRL best practices initiave characteristics of program of information literacy. Available from: <www.ala.org/acrl/nili/bestprac. html>. Acess: 15 Dec. 2003.
- Há necessidade de adoção de uma abordagem cooperativa entre todos os setores da infra-estrutura informacional e da infra-estrutura educacional para o desenvolvimento de produtos e serviços que elevem o aprendizado, onde o diálogo e os relacionamentos são essenciais.

Por se tratar da apresentação de uma base teórica inicial, em síntese, espera-se haver despertado o interesse para um diálogo construtivo sobre a information literacy e sua importância na formação de professores, revendo-se conteúdos e práticas pedagógicas e informacionais, buscando a renovação e a aceitação aos desafios às práticas investigativas em busca de respostas a tantas inquietações, o que certamente irá contribuir para a transformação da realidade que nos cerca, agregando-se maior valor à informação e produção do conhecimento e ao mediador natural desse processo - o profissional da informação.

AZEVEDO, J.B.C. O Projeto de Educação Continuada (PEC) na Universidade Estadual Paulista (UNESP): alguns indicadores avaliatórios. In: BICUDO, M.A.V.; SILVA JÚNIOR, C.A. Formação do educador e avaliação educacional. São Paulo: UNESP, 1999. v.2, p.249-263.

BAZZO, W.A. Ciência, tecnologia e sociedade. Available from: <http://www.campus.oel.org>. Acess: 10 set. 2001.

BELANGER, J. Teacher and research: roles and expectations. Available from: <http://ericae.net/ ercdb/ED342751.htm>. Acess: 1 Nov. 2001.

BELLUZZO, R.C.B. A information literacy como competência necessária à fluência científica e tecnológica na sociedade da informação: uma questão de educação. In: SIMPÓSIO DE ENGENHARIA DE PRODUÇÃO DA UNESP.7, Bauru, 2001. Anais... Bauru, UNESP, 2001. Disponível em: <http:/ /www.simpep.feb.unesp.br/ana8.html>. Acesso em: 4 abr. 2002. 
BOFF, L. Prefácio. In: ASSMAN, H. Reencantar a educação: rumo à sociedade aprendente. 5.ed. Petrópolis: Vozes, 2001. p.11-12.

BRINDLEY, G. Becoming a researcher: teacher-conducted research and professional growth. In: SADTONO, E. (Ed.). Issues in language teacher education. Available from: <http://ercae.net/ericdb/ ED370362.htm> Acess: 10 Nov. 2001.

COOMBS, B. Crossing the borderline between theory \& research and practice: becoming a teacher-researcher. Active Learner, v.4, p.12-16, 1999.

DELORS, J. La educación encierra un tesoro. Madrid: UNESCO/Santillana, 1996.

DELORS, J. Educação: um tesouro a descobrir. 6.ed. São Paulo: Cortez, 2001.

DEMO, P. Educação e qualidade. Campinas: Papirus, 1998.

DUDZIAK, E.A. Competência em informação: a information literacy e o papel educacional das bibliotecas e do bibliotecário. Boletim Informativo do CRB-8, v.10, n.2, p.3-10, 2002.

FLEURY, M.T.L. Aprendizagem e gestão do conhecimento. In: DUTRA, J.S. (Org.). Gestão por competências. São Paulo: Gente, 2001. p.85-96.

FLEURY, A.; FLEURY, M.T.L. Estratégias empresariais e formação de competências. São Paulo: Atlas, 2000.

FUEYO, V.; KOORLAND, M. Teacher as researcher: a synonym for professionalism. Journal of Teacher Education, v.48, n.5, p.336-344, 1997.

GÓMEZ, A.P. O pensamento prático do professor: a formação do professor como profissional reflexivo. In: NOVOA, A., (Coord). Os professores e sua formação. Lisboa: D.Quizote, 1992. p.93-114.

KUENZER, A.Z. As políticas de formação: a constituição da identidade do professor sobrante. Educação \& Sociedade, n.68, p.175, 1999.

LARANJEIRAS, M.I. et al. Referências para a formação de professores. In: BICUDO, M.A.V.; SILVA JÚNIOR, C.A. Formação do educador e avaliação educacional. São Paulo: UNESP, 1999. v.2, p.17-47.
LOERTSCHER, D. The organized investigator (Circular model). Available from: <http://ctap. fcoek.k12.ca.us/ctap/Info.Lit/infolit.html>. Acess: 20 Aug. 2001.

MESSINA, G. Investigación en o investigación acerca de la formación docente: un estado del arte en los noventa. Revista Iberoamericana de Educación, v.19, p.145-207, 1999.

MIRANDA, G.V. Reflexões sobre a avaliação externa do PEC. In: BICUDO, M.A.V.; SILVA JÚNIOR, C.A. (Org.). Formação do educador e avaliação educacional. São Paulo: UNESP, 1999. v.2, p.239-247.

PERRENOUD, P. Construir competências desde a escola. Porto Alegre: Artmed, 1999.

REIMER, K.; BRUCE, B. Building teacher-researcher collaboration: dilemmas and strategies. Available from: <http://ericae.net/ericdb/ED357331 htm> Acess: 10 Nov. 2001.

RODRÍGUEZ, J.G.; BERNAL, E.C. Los profesores en contextos de investigación e innovación. Revista Iberoamericana de Educación, v.25, p.121-154, 2001.

SANTOS, A.R. Metodologia científica. Rio de Janeiro: DP\&A, 1999.

SÃO PAULO. Secretaria de Educação. PEC: formação universitária: projeto básico do programa. São Paulo: UNESP, 2001.

SENGE, P. A quinta disciplina. São Paulo: Best Seller, 1990.

SEVERINO, A. J. Metodologia do trabalho científico. 21.ed. São Paulo: Cortez, 2000.

SOCIEDADE da informação no Brasil: livro verde. Brasília: MEC, 2000.

VILLARDI, R. Iniciação científica na formação do professor: trilhas em construção. In: CALAZAN, J. (Org.). Iniciação científica: construindo o pensamento crítico. São Paulo: Cortez, 1999. p.129-140.

ZEICHNIER, K. Concepções de prática reflexiva no ensino e na formação de professores. In: ZEICHNIER, K. A formação reflexiva de professores: idéias e práticas. Lisboa: Educa, 1993. p.29-52. 